\title{
Role of $1.5 \%$ acetic acid irrigation and medical management in chronic persistent suppurative otitis media
}

\author{
Bhavya Kanakarajulu, Lanke Sowmya*, Teja
} Department of otorhinolaryngology, Santhiram Medical College and General Hospital, Nandyal, Andhra Pradesh,
India

\author{
Received: 31 March 2021 \\ Revised: 13 May 2021 \\ Accepted: 14 May 2021 \\ *Correspondence: \\ Dr. Lanke Sowmya, \\ E-mail: lankesowmya@gmail.com
}

Copyright: (c) the author(s), publisher and licensee Medip Academy. This is an open-access article distributed under the terms of the Creative Commons Attribution Non-Commercial License, which permits unrestricted non-commercial use, distribution, and reproduction in any medium, provided the original work is properly cited.

\begin{abstract}
Background: Chronic ear discharge in chronic suppurative otitis media (CSOM) persisting for more than two weeks has become difficult to treat for ENT specialists due to resistance to the available antibiotics and patient's affordability for its cost. Also, biofilms have been responsible for the disease and cause tympanic membrane perforation and deafness. The use of $1.5 \%$ acetic acid irrigation acts as an antiseptic, and altering the middle ear's $\mathrm{pH}$ to treat otorrhea in CSOM needs to be studied. Aim of the study to assess results of $1.5 \%$ acetic acid irrigation and topical and systemic antibiotic in CSOM and to consider the most appropriate medical management

Methods: A total of 100 patients of CSOM was divided equally into two groups. Group 1 patients were treated with $1.5 \%$ acetic acid irrigation every other day, and group 2 was treated with topical and systemic antibiotics three drops' times daily. Follow up of both groups every week up to symptomatic relief.

Results: Otorrhoea resolution in the group treated with acetic acid was $88 \%$, and healing of perforation was noted in $28 \%$, while the failure rate of $12 \%$.

Conclusions: Medical management of persistent CSOM with tubotympanic type by frequent aural cleaning, $1.5 \%$ acetic acid irrigation can be the more desirable choice than the topical and oral antibiotics. It is safe without any side effects and economical. Alteration of ear canal PH is one of the main factors for healing, in addition to mechanical disruption of biofilm and removal of deep-seated debris.
\end{abstract}

Keywords: CSOM, URT, EAM

\section{INTRODUCTION}

Chronic otitis media is an infection of the middle ear lasting for more than two weeks, mostly holds perforation of the tympanic membrane and discharging. CSOM is an insidious onset and persistent disease. It is one of the most common infections in the otorhinolaryngology department and resistant to current antibiotics. ${ }^{1}$

Medical management of chronic suppurative otitis media for the dry ear is essential before surgical treatment. Biofilms are the most prevalent microbial form in the biological environment and play a central role in chronic infections. $^{2,3}$ chronic suppurative otitis media is considered a biofilm disease, and it also explains the observed resistance to antibiotics. ${ }^{4}$

Ear, nose, and throat (ENT) infections are common clinical problems occurring in the general population and cause severe morbidity and frailty. These infections affect the normal daily functioning of both adults and children and are the frequent cause of absenteeism from work and school among school-aged children. ${ }^{5}$ As with other infections of the upper respiratory tract (URT), ear infections such as CSOM are of great concern, especially in developing countries. ${ }^{8}$ 
There are no published guidelines for the treatment of CSOM. The drawback of treatment using antibiotics both orally and parenterally includes cost, adverse effects, toxic reaction, and inconvenience for patients. There is no consensus among general and specialist physicians about the medical management of chronic suppurative otitis media. However, there is general agreement that an aural toilet must be part of the standard medical treatment for CSOM.

The recognition that chronic otolaryngological bacterial infections are biofilm-related has been the impetus for developing new technologies for the study of biofilms and their prevention and treatment. Physical removal or disruption of bacterial biofilm effectively treats this chronic infection but is often not clinically feasible. There are currently no specific reliable alternative methods to prevent or eradicate microbial biofilm in patients. ${ }^{8}$ Several strategies have been proposed and are under investigation.

The objective of study was to consider the most appropriate medical treatment modality for patients of CSOM by comparing the efficacy of aural cleansing and irrigation with dilute acetic acid with topical and systemic antibiotics.

\section{Aim and objectives}

Aim and objectives of the study were to assess results of acetic acid irrigation and topical and systemic antibiotic in CSOM and consider the most appropriate medical management.

\section{METHODS}

\section{Study type}

This prospective observational study was carried at the department of otolaryngology, Santhiram general hospital.

\section{Sampling technique}

Sampling technique used for the study was simple random technique.

\section{Study population}

The study population included in the current study were $=100$.

\section{Inclusion criteria}

Inclusion criteria included those patients giving informed and written consent, patient with the active mucosal disease with defect of pars tensa and patients having symptoms for more than four weeks.

\section{Exclusion criteria}

Exclusion criteria excluded a patient who has not given inform and written consent, dry ear with CSOM and CSOM with attico antral type and serous otitis media.

\section{Sample size}

A study done in 100 patients in the department of otorhinolaryngology at Santhiram medical college and general hospital, for duration of 5 months (November 2020-March 2021.)

Sample size calculation formula $=4 \mathrm{pq} / \mathrm{d} 2$,

Estimated prevalence according to previous studies: ${ }^{6}=5.2 \%$,

$\mathrm{q}=100$-prevalence,

$\mathrm{d}=$ absolute precision $=5$,

$4 \times 5.2 \times 94.8 / 5 \times 5=78.8$ rounded off to 100

\section{Evaluation criteria}

Initial evaluation for the otological symptom score were done at baseline (at day 0) before treatment. The effectiveness $1.5 \%$ acetic acid was compared with effectiveness of ciprofloxicin on the basis of reduction in otological symptoms score involving middle ear and external auditory meatus (EAM) in 14 days after treatment and by telephone contact in the case of patients who had not come in followed up. Patients were monitored continuously throughout the study for any adverse effects. Safety monitoring was performed continuously throughout the study. All ADE spontaneously reported by the subjects or elicited by the investigators were recorded. A difference of $10 \%$ in clinical cure rates was assumed to be the largest clinically acceptable effect for which equivalence could be accepted (equivalence limit). Considering the true mean difference between the two treatment groups at zero and the expected standard deviation of $10 \%$ in the study population.

\section{Effectiveness parameters}

Number of subjects achieving "treatment success" in each treatment group were considered to be the effectiveness parameter. Treatment success was based on changes in the ontological symptoms scores at day 14 visit. It was subdivided into two categories: (a) "clinical cure" if the ontological symptom score was <3 at day 14 visit or (b) "clinical improvement" if the ontological symptom score was between 3 and 5 on day 14 . "Treatment failure" was declared if there was no change or increase in the baseline otological symptom score or $>5$ otological symptoms score on day 14 . 
Table 1: Otological symptom score. ${ }^{7}$

\begin{tabular}{|lllll|}
\hline Signs/symptoms & Score $\mathbf{0}$ & Score 1 & Score 2 & Score 3 \\
\hline Amount of discharge & No discharge & $\begin{array}{l}\text { Confined to middle } \\
\text { ear }\end{array}$ & Entering into EAM & $\begin{array}{l}\text { Completely filling } \\
\text { EAM }\end{array}$ \\
\hline Type of discharge & Absent & Mucoid & Mucopurulent & Purulent \\
\hline Tinnitus & Absent & Mild & Moderate & Severe \\
\hline
\end{tabular}

\section{Statistical analysis}

Data was collected and entered into Microsoft excel and analysed using SPSS software version 25 by appropriate statistical tests. Results were expressed in the form of mean and standard deviation.

\section{Methodology}

A simple Randomized study done in 100 patients in the department of otorhinolaryngology at santhiram medical college and general hospital, for duration of 5 months (November 2020-March 2021 subjects of any sex, aging 10 years or more, diagnosed with tubotympanic type of CSOM based upon detailed history and otoscopic examination were included in the study. Explained about the research and requested to participate, took informed and written consent from each of the subjects. The institutional ethics committee approved study.

Patients with atticoantral types of chronic suppurative otitis media, cholesteatoma, known cases of hypersensitivity to acetic acid, immunocompromised individuals, pregnant females, and lactating mothers, and patients not willing to participate were excluded from the study. Patients were then randomly divided into two groups. Group I was given topical $1.5 \%$ acetic acid, and group II was given topical antibiotics in three otic drops three times daily and oral antibiotics. All the cases were followed up weekly.

The ear was thoroughly cleaned with dry mopping before a swab of the middle ear being taken for microscopy and culture. In the group treated with aural cleansing and irrigation with acetic acid, the patients were advised to visit our hospital every other day. At each visit, the external auditory canal and middle ear cavity were cleaned with the suction tube as clearly as possible and irrigated with diluted acetic acid $\left(2 \mathrm{ml}, 37^{\circ} \mathrm{C}\right)$ using $1 \mathrm{ml}$ syringe. The patients were advised for self-irrigation once daily at home. The criteria for discontinuing the treatment were no discharge in the morning, the external canal should be dry and clean and thirdly, the ear mucosa should not be wet or oedematous.

In another group, the external auditory canal and middle ear cavity were thoroughly cleaned by dry mopping and suction followed by the installation of topical antibiotics, i.e., ciprofloxacin ear drop for 3 months. The topical antibiotic was combined with systemic antibiotics i.e., ciprofloxacin $500 \mathrm{mg}$ twice daily for 15 days. Patients followed for 3 months, and the following signs have noted the absence of discharge, healing of perforation, and status of middle ear mucosa.

\section{RESULTS}

A total of 100 patients were included in this study of age range 10-60 years (mean age-35), 62 were male, and 38 were female.

Table 2: Age wise distribution in both the groups.

\begin{tabular}{|llll|}
$\begin{array}{l}\text { Age } \\
\text { (years) }\end{array}$ & $\begin{array}{l}\text { Group 1 } \\
(\%)\end{array}$ & $\begin{array}{l}\text { Group 2 } \\
(\%)\end{array}$ & $\begin{array}{l}\text { Total } \\
(\%)\end{array}$ \\
\hline $\mathbf{1 0 - 1 9}$ & $14(28)$ & $7(14)$ & $21(21)$ \\
\hline $\mathbf{2 0 - 2 9}$ & $12(24)$ & $26(52)$ & $38(38)$ \\
\hline $\mathbf{3 0 - 3 9}$ & $8(16)$ & $9(18)$ & $17(17)$ \\
\hline $\mathbf{4 0 - 4 9}$ & $10(20)$ & $4(8)$ & $14(14)$ \\
\hline $\mathbf{5 0 - 5 9}$ & $6(12)$ & $4(8)$ & $10(10)$ \\
\hline
\end{tabular}

Table 3: Gender wise distribution in both the groups.

\begin{tabular}{|lll|}
\hline Gender & Group 1 $(\%)$ & Group 2(\%) \\
\hline Male & $28(56)$ & $34(68)$ \\
\hline Female & $22(44)$ & $16(32)$ \\
\hline
\end{tabular}

Discharge and hearing loss were presenting complaints in all patients, while tinnitus was present in $28 \%$, and vertigo was not a complaint in this study group. Around $27 \%$ of patients had mild, $63 \%$ patients had moderate, and $10 \%$ patients had a severe discharge. Bilateral ear disease was found in 24 patients, right ear in 50 patients, and left ear in 26 patients. Distribution of various sizes of perforation in 124 ears 32 had SCP, $60 \mathrm{MCP}, 26$ had $\mathrm{LCP}$, and 10 patients had a subtotal perforation.

In group A (patient treated with acetic acid): We found a dry ear in 44 patients $(88 \%)$ in the mean of 27.3 days. 17 patients $(34 \%)$ had dry ear in 15 days, 14 patients $(28 \%)$ in 1 month, 10 patients $(20 \%)$ in one and half month and 2 patients $(4 \%)$ in 2 months. While in 1 patient $(2 \%)$, we could achieve dry ear after 3 months.

Perforation healed in 14 patients $(28 \%)$. The minimum period for healing was 1 month and maximum 3 months.

In group B (patient treated with topical and systemic antibiotic): We found a dry ear in 26 patients $(52 \%)$ in the mean of 31.0 days. 10 patients $(20 \%)$ had dry ear in 
15 days, 8 patients (16\%) in 1 month, 5 patients $(10 \%)$ in one and half month and 1 patient $(2 \%)$ in 2 months. While in 2 patients $(4 \%)$, we could achieve dry ear after 3 months.

Perforation healed in 6 patients (12\%). Minimum period for healing was 1 month and a maximum 3 months.

Table 4: Efficacy in both groups in achieving dry ears in CSOM.

\begin{tabular}{|lll|}
\hline No. of days & $\begin{array}{l}\text { Group } \mathbf{1}(\mathbf{1 . 5} \% \\
\text { acetic acid) }(\%)\end{array}$ & $\begin{array}{l}\text { Group 2 } \\
\text { (antibiotic drops) } \\
(\%)\end{array}$ \\
\hline $\mathbf{1 5}$ days & $17(34)$ & $10(20)$ \\
\hline 1 month & $14(28)$ & $8(16)$ \\
\hline $\mathbf{1} 1 \mathbf{2}$ month & $10(20)$ & $5(10)$ \\
\hline $\mathbf{2}$ months & $2(4)$ & $1(2)$ \\
\hline 3 months & $1(2)$ & $2(4)$ \\
\hline Total & $44(88)$ & $26(52)$ \\
\hline
\end{tabular}

Table 5: Intergroup comparison.

\begin{tabular}{|llll|} 
Groups & $\begin{array}{l}\text { Total no. of } \\
\text { people }\end{array}$ & $\begin{array}{l}\text { No. of people } \\
\text { cured }\end{array}$ & Mean \pm SD \\
\hline Group 1 & 50 & 44 & $8.8 \pm 7.12$ \\
\hline Group 2 & 50 & 26 & $5.2 \pm 3.83$ \\
\hline
\end{tabular}

\section{DISCUSSION}

Management of otorrhea in CSOM has become a difficult task for otologists. Because of the emerging resistance to antibiotics, patient compliance for long-term treatment and biofilm formation by organisms.

Roland, in 2002, proposed that biofilms are the likely cause of CSOM, which would explain the observed resistance to antibiotic therapy. ${ }^{8}$ Nowadays biofilms are thought to play a central role in chronic infections and infections associated with implantable devices. ${ }^{4}$

Our study shows that careful irrigation with $1.5 \%$ acetic acid resolved otorrhoea in 44 patients. Over a mean period of 27.3 days, the follow-up period was every 15 days for 3 months. $14(28 \%)$ of them had spontaneous closure of the tympanic membrane.

Our finding for dry ear and healed perforation is comparable with that of a study done by Choi et al., i.e., (79.5\% achieve dry ear and noticed no healing) but slightly on the higher side. It may be because of more irrigation. The result of Mallik et al and Chhangani and Goyal in the treatment of CSOM with acetic acid is much lower i.e., $40 \%$, than our findings. ${ }^{1,7-10}$

Failure of treatment in our study was in $16 \%$ ( 8 patients) compared to $15 \%$ failure rate in the study of Choi et al and $20.40 \%$ in the study of Mailk et al and Chhangani et al, but it is insignificant. ${ }^{1,9,10}$
The mechanism underlying aural cleansing and irrigation with acetic acid appears to be: Historically, it has been used in the management of infection since the time of Hippocrates (400BC) and has a broad bactericidal spectrum covering both gram-positive and gram-negative organisms. Acetic acid (plain, white household vinegar) is an antiseptic that treats infections caused by bacteria or fungus. It is also a commonly prescribed home remedy for the treatment of otitis externa. This medication will not treat a middle ear infection (otitis media), even that some writer or prescriber is used as an irrigation antiseptic for patients suffering from ear discharge in CSOM. Treatment involves copious and frequent irrigation of the ear with $1.5 \%, 2 \%$ acetic acid.

We had a failure of treatment in 6 patients' i.e., $12 \%$. Duration of otorrhoea, longer duration proved most challenging to resolve. The degree of inflammation and size of perforation did not affect the outcome.

The advantages of this treatment are essential from the socioeconomic point of view. The cost of therapy is low compared with antibiotic treatment. The choice of antimicrobial treatment to be combined with an aural toilet is a highly contentious issue. A 1985 survey of pediatricians in Dallas, Texas (USA) found that $79 \%$ would prescribe topical antibiotics, and $100 \%$ would use oral antibiotics.

In search of a cheap yet effective medical treatment for CSOM, the primary consideration apart from effectiveness is the potential risk of ototoxicity.

Ludman and Nelson advocated similar approaches and cited potential ototoxic effects as a significant disadvantage of topical antibiotics. On the other hand, most otolaryngologists recommend topical antibiotic therapy and point out the poor penetration by most antibiotics into a devascularised middle ear mucosa masked with subepithelial scarring and thickening. ${ }^{14-16}$

Our findings of achieving dry ear in $58 \%$ of patients of CSOM managed with a topical and oral antibiotic for 15 days preceded with aural toilet are in accordance with those mentioned in the literature, the Cochrane review observed $50 \%$ of otorrhoea resolution, Fradis et al observed similar results, 47.4 and $55 \%$ of otorrhoea resolution rates in his study while Supiyaphun et al found that topical and systemic antibiotics resolution of ear discharge (76.9 and 37\%, respectively) were higher. ${ }^{12,12}$

The higher $\%$ of the resolution of otorrhoea shown by various studies mentioned in literature maybe because of the fact that these studies are from western world, where people are comparatively more particular and conscious about their health problem. Gupta et al shows similar results from Gwalior or, India for the period from Nov 2011 to Sep 2013, where otorrhoea resolution was seen in $84 \%$ (42/50) cases of CSOM (tubotympanic type) using $2 \%$ acetic acid versus $58 \%(29 / 50)$ using ciprofloxacin 
eardrops for 3 months and ciprofloxacin $500 \mathrm{mg}$ twice daily for 15 days at 3 months follow up. Here efficacy of antiseptic was superior to ciprofloxacin eardrops.

Although combination antibiotics are effective in resolving otorrhoea, adding oral antibiotics to topical antibiotics and aural toilet increases the cost without increasing the success rate. This confirms the difficulty of systemic drug penetration through the devascularized, fibrotic mucosa of the middle ear and mastoid. It also emphasizes the critical role of local treatment. The basic reason for combining oral antibiotics with topical was that personal hygiene, sanitation, and other aggravating factors play an important role in the disease process in our country. Most of the patients in our study belonged to the low socioeconomic group. However, the drawbacks of treatment with antibiotics include cost, adverse effects, toxic reaction, and inconvenience for our patients.

Topical quinolone antibiotics can clear aural discharge better than systemic antibiotics, while topical nonquinolone antibiotics (without steroids) or antiseptic results are less clear. Further studies should clarify topical nonquinolone and antiseptic effectiveness, assess long-term outcomes (resolution, healing, hearing, or complications) and include additional safety assessments, mainly to explain the risks of ototoxicity and whether there may be few adverse events with topical quinolones than other topical or systemic treatment.

\section{CONCLUSION}

Medical management of CSOM without cholesteatoma by frequent aural cleaning and irrigation using dilute $1.5 \%$ acetic acid can be a more desirable choice than topical and oral antibiotics. It is a safe and low cost without producing any side effects. Alteration of $\mathrm{pH}$ of the ear canal is one of the main factors for healing and mechanical disruption of biofilm and removal of deepseated debris in poorly vascularized sites such as bones.

Funding: No funding sources

Conflict of interest: None declared

Ethical approval: The study was approved by the Institutional Ethics Committee

\section{REFERENCES}

1. Choi HG, Park KH, Park SN, Jun BC, Lee DH, Yeo SW. The appropriate medical management of methicillin-resistant Staphylococcus aureus in chronic suppurative otitis media. Acta Otolaryngol. 2010;130(1):42-6

2. Post JC, Hiller NL, Nistico L, Stoodley P, Ehrlich GD. The role of biofilms in otolaryngologic infections (Update 2007). Curr Opin Otolaryngol Head Neck Surg. 2007;15(5):347-51.
3. Jones CE, Kennedy JP. Treatment options to manage wound biofilm. Adv Wound Care (New Rochelle). 2012;1(3):120-6.

4. Macassey E, Dawes P.Biofilms and their role in otorhinolaryngological disease. J Laryngol Otol. 2008;122:1273-8.

5. Chronic Suppurative Otitis media: burden of illness and management options. Child and Adolescent Health and Development, Prevention of Blindness and Deafness. World Health Organization. Geneva, Switzerland. 2004;14-9.

6. WHO/PDH Prevention of hearing impairment from chronic Otitis media. Report of WHO/CIBA Foundation workshop, Geneva. 1996;19-21.

7. Vishwakarma K, Khan FA, Nizamuddin S, Yadav L. Role of Topical Acetic Acid in Comparison to Gentamicin for the Management of Chronic Suppurative Otitis Media. Int Arch BioMed Clin Res. 2015;1(1):13-6.

8. Roland PS. Chronic suppurative otitis media: a clinical overview. Ear Nose Throat. 2002;81:8-11.

9. Malik MK, Dayal D, Khan AM. In vitro and in vivo evaluation of change of local $\mathrm{pH}$ on bacteria in chronic suppurative otitis media. J Laryngol Otol. 1975;89:837-43.

10. Chhangani DL, Goyal OP. Bacteriological study in chronic suppurative otitis media. Indian $\mathrm{J}$ Otol. 1976;28:41-5.

11. Fradis M, Brodsky A, Ben-David J, Srugo I, Larboni J, Podoshin L. Chronic otitis media treated topically with ciprofloxacin and tobramycin. Arch Otolaryngol Head Neck Surg. 1997;123:1057-60.

12. Supiyaphun P, Kerekhanjanarong V, Koranasophonepun J, Sastarasadhit V. Comparison of ofloxacin otic solution with oral amoxicillin plus chloramphenicol ear drop in the treatment of chronic suppurative otitis media with acute exacerbation. J Med Assoc Thail. 200;83(1):61-8.

13. Fabricant ND, Perlstein MA. pH of the cutaneous surface of the external auditory canal. Arch Otolaryngol. 1949;49:201-9.

14. Ludman H. Discharge from the ear: otitis externa and acute otitis media. BMJ. 1980;281:1616-7.

15. Nelson SM, Berry RI. Ear disease and hearing loss among Navajo children: a mass survey. Laryngoscope. 1984;94:316-23.

16. Dellamonica P, Choutet P, Lejeune JM, Lucht F, Morgon A, Pessey JJ et al. Efficacy and safety of cefotiam hexetil in the treatment of chronic otitis media. A comparative double-blind randomized study versus cefuroxime axetil. Med Mal Infect. 1995;25(5):733-9.

Cite this article as: Kanakarajulu B, Sowmya L, Teja. Role of $1.5 \%$ acetic acid irrigation and medical management in chronic persistent suppurative otitis media. Int J Otorhinolaryngol Head Neck Surg 2021;7:1010-4. 